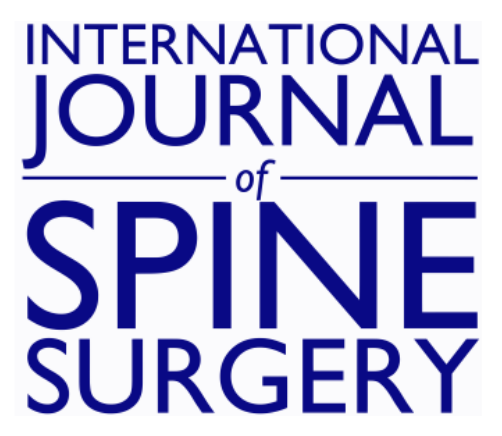

\title{
Response to Letter to the Editor by Soffin et al.
}

Elliot D.K. Cha, Conor P. Lynch, James M. Parrish, Nathaniel W. Jenkins, Asokumar Buvanendran and Kern Singh

Int J Spine Surg 2021, 15 (5) 850-852

doi: https://doi.org/10.14444/8110

http://ijssurgery.com/content/15/5/850

This information is current as of April 26, 2023.

Email Alerts Receive free email-alerts when new articles cite this article. Sign up at:

http://ijssurgery.com/alerts

The International Journal of Spine Surgery

2397 Waterbury Circle, Suite 1,

Aurora, IL 60504, Phone: +1-630-375-1432 


\section{Response to Letter to the Editor by Soffin et al.}

To the editor of IJSS,

Dr Soffin and colleagues raised several points regarding the use of a multimodal analgesia (MMA) protocol for patients undergoing lumbar fusion in an ambulatory surgical center (ASC). Their insight into the use of a number of agents in our protocol is appreciated and will only help clarify and support the use of MMA or enhanced recovery after surgery protocols in the spine surgery community.

To Dr Soffin et al's point regarding the decision to use oxycodone controlled release for pre-emptive analgesia, we appreciate the concern of its off-label use. One of the primary goals of our MMA protocol was to minimize the use of intravenous postoperative opioids commonly administered via a patient-controlled analgesia (PCA) machine. This shift away from PCA in the ambulatory setting would allow for a significant reduction in the risk of pruritus, sedation, and postoperative nausea and vomiting, which are among the most common complications for ASC patients, ${ }^{1,2}$ as well as the risk for significant cognitive impairment and/or respiratory depression., In keeping with this goal, the use of oxycodone controlled release preoperatively was aimed at taking full advantage of peak preemptive analgesic effects. It may be suggested that this form of oxycodone use may place patients at higher risk for postoperative respiratory depression; however, administration at the preoperative, rather than postoperative, timepoint and application of appropriate patient selection criteria can mitigate the negative effects by maximizing overlap between the peak window of opioid effects and the period of direct clinical care. Indeed, its preoperative use is defined as "off-label", but careful dosage selection of $\leq 10 \mathrm{mg}$ was made to avoid the risk of respiratory depression, which is largely in line with the recommendations by the Food and Drug Administration (FDA) (section 2.2) for approved use in opioid intolerant/naive patients. ${ }^{5}$ Furthermore, the vast majority of medications prescribed by physicians are "off label". ${ }^{-9}$

Another point that Dr Soffin and colleagues raise is the risk brought on by the use of gabapentinoids in our MMA protocol as well as its use in conjunction with oxycodone. Concern for increased risk for overdose death and respiratory failure after discharge from an ASC is not without merit, as the authors highlighted past FDA warnings and recent randomized controlled studies that may call into question its efficacy. Most important is the recent systematic review of 281 clinical trials that reported no clinical benefit to the perioperative use of gabapentinoids. ${ }^{10}$ However, authors of the systematic review reported a high risk of bias $(46 \%)$. Additionally, these same authors also reported that the similar levels of postoperative acute pain and opioid administration in both gabapentinoid and nongabapentinoid groups were based on low- to very low-quality evidence. Furthermore, even a robust review, such as this study, highlighted that the risk of respiratory depression following the use of gabapentinoids with opioids was not significantly different. Our own review of published spine literature pertaining to the use of gabapentinoids in MMA protocols has also largely suggested that its implementation can decrease overall opioid consumption while providing safe analgesia for patients. ${ }^{3,11-20}$ It then stands to reason that our goal of implementing pregabalin was to reduce central sensitization and thereby reduce analgesic requirements. Thus far, our experience with the concomitant use of muscle relaxants (cyclobenzaprine), long-acting opioids (oxycodone controlled release), and gabapentinoids (pregabalin) among ASC spine patients continues to be positive, with few if any readmissions for severe respiratory depression following discharge from an ASC. To further curb the risk of adverse events, the protocol implements a dosage of postoperative gabapentin (75 $\mathrm{mg}$ ) that is also in alignment with FDA recommendations (section 2.6) when used with opioids. ${ }^{5} \mathrm{Dr}$ Soffin and colleagues do raise a valid point regarding the role of gabapentinoids in MMA protocols in the long term and are commended for their own randomized controlled trial detailing the successful use of an enhanced recovery pathway for lumbar fusion patients. However, what is unclear is the claim that these authors have eliminated the regular use of gabapentinoids, while citing a study in which gabapentin is used in their protocol. ${ }^{21}$ We agree that this represents an important topic for exploration, but more empirical evidence is required to draw any 
meaningful conclusions and permanent adjustments to our protocol. However, the authors of this paper have carried out randomized controlled trials with 240 orthopedic surgery patients that have demonstrated efficacy with gabapentinoids. ${ }^{22}$

Lastly, coprescribing multiple opioid analgesics in the postoperative period has incited questioning behind its use by Dr Soffin et al. We agree that any reliance on opioid medications for pain control is not ideal, especially given associated potential for adverse events as well as the recommendations of several major pain societies to minimize their use. However, while significant advances have been made in perioperative analgesia, opioid medications remain an important aspect of effective pain control for patients undergoing major surgery. The focus of multimodal postoperative analgesia has been to significantly reduce the use of intravenous analgesics while maintaining adequate analgesia. As such, use of tramadol, which is a known weak $\mu$-opioid receptor agonist, was implemented to minimize the use of more potent opioids (oxycodone). While our protocol does incorporate the use of some narcotic medications, their use, as described in the study of discussion, ${ }^{23}$ is at half dosage, as recommended by the FDA, ${ }^{5}$ and is primarily for breakthrough pain in the postoperative recovery room as well as for patients discharged on postoperative day 0 . Furthermore, there is sufficient evidence that controlling acute pain after surgery can reduce chronic pain. ${ }^{22}$ Also, it is important to note that current alternative protocols detailed in the literature may actually involve greater or less tightly controlled reliance on opioid-based analgesia. For example, the MMA protocol published by Soffin et al includes no preoperative opioid medications but involves the use of PCA with intravenous hydromorphone in addition to tramadol for postoperative pain control. $^{21}$ In fact, Soffin et al report a median postoperative opioid consumption of 62 and 57.5 oral morphine equivalents on the day of surgery, ${ }^{8,21}$ which is nearly twice the mean value observed for patients in our cohort.

While Dr. Soffin et al raise valid concerns about the use of multiple opioid analgesics postoperatively, this aspect of our protocol has significant benefit to patients. Specifically, the use of multiple different analgesic medications allows for synergistic pain control while minimizing the dosage and associated side effects of any one medication. ${ }^{4}$ Our practice strives to standardize our lumbar fusion "pathway" to the greatest extent possible, which has been instrumental to our success with ambulatory lumbar fusion procedures. The use of a standardized MMA protocol rather than more variable PCA for postoperative pain control allows for greater predictability and uniformity, reducing the potential for errors or complications in the postoperative period.

In summary, Dr. Soffin et al raise concerns regarding the use of individual components of our MMA protocol. However, it is our belief that, when considered in its entirety, our protocol continues to provide safe yet effective analgesia for appropriately selected patients.

\section{REFERENCES}

1. Chung F, Mezei G. Factors contributing to a prolonged stay after ambulatory surgery. Anesth Analg. 1999;89(6):13521359.

2. Elvir-Lazo OL, White PF, Yumul R, Cruz Eng H. Management strategies for the treatment and prevention of postoperative/postdischarge nausea and vomiting: an updated review. F1000Res. 2020;9:F1000 Faculty Rev-983. doi:10. 12688/f1000research.21832.1

3. Rajpal S, Gordon DB, Pellino TA, et al. Comparison of perioperative oral multimodal analgesia versus IV PCA for spine surgery. J Spinal Disord Tech. 2010;23(2):139-145.

4. Singh K, Bohl DD, Ahn J, et al. Multimodal analgesia versus intravenous patient-controlled analgesia for minimally invasive transforaminal lumbar interbody fusion procedures. Spine (Phila Pa 1976). 2017;42(15):1145-1150. doi:10.1097/brs. 0000000000001992

5. Purdue Pharma L.P. (Stamford, CT). Highlights of prescribing information. https://www.fda.gov/media/131026/ download. Accessed April 11, 2021.

6. Soffin EM, Wetmore DS, Barber LA, et al. An enhanced recovery after surgery pathway: association with rapid discharge and minimal complications after anterior cervical spine surgery. Neurosurg Focus. 2019;46(4):E9. doi:10.3171/2019.1. FOCUS18643

7. Soffin EM, Vaishnav AS, Wetmore DS, et al. Design and implementation of an enhanced recovery after surgery (ERAS) program for minimally invasive lumbar decompression spine surgery: initial experience. Spine (Phila Pa 1976). 2019;44(9):E561-E570.

8. Soffin EM, Freeman C, Hughes AP, et al. Effects of a multimodal analgesic pathway with transversus abdominis plane block for lumbar spine fusion: a prospective feasibility trial. Eur Spine J. 2019;28(9):2077-2086.

9. Soffin EM, Wetmore DS, Beckman JD, et al. Opioid-free anesthesia within an enhanced recovery after surgery pathway for minimally invasive lumbar spine surgery: a retrospective matched cohort study. Neurosurg Focus. 2019;46(4):E8. doi:10. 3171/2019.1.FOCUS18645

10. Verret M, Lauzier F, Zarychanski R, et al. Perioperative use of gabapentinoids for the management of postoperative acute pain: a systematic review and meta-analysis. Anesthesiology. 2020;133(2):265-279.

11. Smith J, Probst S, Calandra C, et al. Enhanced recovery after surgery (ERAS) program for lumbar spine fusion. Perioper Med (Lond). 2019;8:4. doi:10.1186/s13741-019-0114-2

12. Haffner M, Saiz AM Jr, Nathe R, et al. Preoperative multimodal analgesia decreases 24 -hour postoperative narcotic 
consumption in elective spinal fusion patients. Spine $J$. 2019;19(11):1753-1763.

13. Momon A, Verdier B, Dolomie J-O, et al. A single preoperative administration of dexamethasone, low-dose pregabalin, or a combination of the 2 , in spinal surgery, does not provide a better analgesia than a multimodal analgesic protocol alone. Clin J Pain. 2019;35(7):594-601.

14. Raja S DC, Shetty AP, Subramanian B, Kanna RM, Rajasekaran $\mathrm{S}$. A prospective randomized study to analyze the efficacy of balanced pre-emptive analgesia in spine surgery. Spine J. 2019;19(4):569-577.

15. Rajpal S, Hobbs SL, Nelson EL, et al. The impact of preventative multimodal analgesia on postoperative opioid requirement and pain control in patients undergoing lumbar fusions. Clin Spine Surg. 2020;33(3):E135-E140.

16. Kim S-I, Ha K-Y, Oh I-S. Preemptive multimodal analgesia for postoperative pain management after lumbar fusion surgery: a randomized controlled trial. Eur Spine J. 2016;25(5):1614-1619.

17. Vasigh A, Jaafarpour M, Khajavikhan J, Khani A. The effect of gabapentin plus celecoxib on pain and associated complications after laminectomy. J Clin Diagn Res. 2016;10(3):UC04-UC08.

18. Kim JC, Choi YS, Kim KN, Shim JK, Lee JY, Kwak YL. Effective dose of peri-operative oral pregabalin as an adjunct to multimodal analgesic regimen in lumbar spinal fusion surgery. Spine (Phila Pa 1976). 2011;36(6):428-433.

19. Garcia RM, Cassinelli EH, Messerschmitt PJ, Furey CG, Bohlman HH. A multimodal approach for postoperative pain management after lumbar decompression surgery: a prospective, randomized study. J Spinal Disord Tech. 2013;26(6):291297.

20. Mathiesen O, Dahl B, Thomsen BA, et al. A comprehensive multimodal pain treatment reduces opioid consumption after multilevel spine surgery. Eur Spine J. 2013;22(9):2089-2096.

21. Soffin EM, Beckman JD, Tseng A, et al. Enhanced recovery after lumbar spine fusion: a randomized controlled trial to assess the quality of patient recovery. Anesthesiology. 2020;133(2):350-363.

22. Buvanendran A, Kroin JS, Della Valle CJ, Kari M, Moric M, Tuman KJ. Perioperative oral pregabalin reduces chronic pain after total knee arthroplasty: a prospective, randomized, controlled trial. Anesth Analg. 2010;110(1):199207.

23. Parrish JM, Jenkins NW, Brundage TS, et al. Outpatient minimally invasive lumbar fusion using multimodal analgesic management in the ambulatory surgery setting. Int $J$ Spine Surg. 2020;14(6):970-981. doi:10.14444/7146

Elliot D.K. Cha, MS

Department of Orthopaedic Surgery, Rush University Medical Center, Chicago, Illinois

Conor P. Lynch, MS

Department of Orthopaedic Surgery, Rush University Medical Center, Chicago, Illinois

James M. Parrish, MD

Department of Orthopaedic Surgery, Rush University Medical Center, Chicago, Illinois

Nathaniel W. Jenkins, MD

Department of Orthopaedic Surgery, Rush University Medical Center, Chicago, Illinois

Asokumar Buvanendran, MD

Department of Anesthesiology, Rush University Medical Center, Chicago, Illinois

Kern Singh, MD

kern.singh@rushortho.com

Department of Orthopaedic Surgery, Rush University Medical Center, Chicago, Illinois

Published 3 December 2021

This manuscript is generously published free of charge by ISASS, the International Society for the Advancement of Spine Surgery. Copyright (C) 2019 ISASS. To see more or order reprints or permissions, see http://ijssurgery.com. 